\title{
Production of bFGF monoclonal antibody and its inhibition of metastasis in Lewis lung carcinoma
}

\author{
YANQING YANG $^{1 *}$, ZHENMING LUO $^{1 *}$, YIYANG QIN $^{1}$, YU ZHOU $^{2}$, \\ LONGCAI GONG ${ }^{1}$, JIANFANG HUANG ${ }^{1}$ and HONG WANG ${ }^{1}$ \\ ${ }^{1}$ Guangdong Province Key Laboratory of Molecular Immunology and Antibody Engineering, Biomedicine \\ Translational Institute, Jinan University, Guangzhou, Guangdong 510640, P.R. China; ${ }^{2}$ Department of \\ Anesthesia and Perioperative Care, University of California, San Francisco, CA 94122, USA
}

Received January 26, 2016; Accepted May 18, 2017

DOI: $10.3892 / \mathrm{mmr} .2017 .7099$

\begin{abstract}
Basic fibroblast growth factor (bFGF) and fibroblast growth factor receptor 1 (FGFR1) are associated with drug resistance in lung cancer. In the present study, mouse monoclonal antibodies (mAb) against human bFGF, targeting the binding site of bFGF with FGFR1 were produced, and the antitumor activity and inhibition of metastasis was studied in Lewis lung carcinoma (LLC). A total of four hybridoma cell strains that stably secreted bFGF mAb were obtained. mAbE12 was selected as the most effective for use in the following studies, with a relative affinity constant of $5.66 \times 10^{8} \mathrm{l} / \mathrm{mol}$. mAbE12 was demonstrated to inhibit cell proliferation and tumor growth in vitro and in vivo. Furthermore, mAbE12 blocked migration and metastasis of LLC cells in vitro and in vivo. This occurred due to a mAbE12-induced upregulation of E-cadherin expression through the protein kinase B-glycogen synthase kinase 3 $\beta$-Snail pathway. These results suggested that mAbE12 may be a potential antibody for the treatment of lung cancer.
\end{abstract}

\section{Introduction}

Metastasis is responsible for $90 \%$ of cases of cancer-associated mortality, including lung cancer. Tumor metastasis includes

Correspondence to: Professor Hong Wang, Guangdong Province Key Laboratory of Molecular Immunology and Antibody Engineering, Biomedicine Translational Institute, Jinan University, 601 Huangpu Road, Guangzhou, Guangdong 510640, P.R. China E-mail: wanghonghlj@qq.com

*Contributed equally

Abbreviations: bFGF, basic fibroblast growth factor; $\mathrm{mAb}$, monoclonal antibody; FGFR, fibroblast growth factor receptor; EGFR, epidermal growth factor receptor; ELISA, enzyme linked immunosorbent assay; EMT, epithelial mesenchymal transition; CCK-8, Cell Counting Kit-8; LLC, Lewis lung carcinoma; Fv, fragment of variable region

Key words: bFGF, monoclonal antibody, lung cancer, metastasis two processes: An initial invasion of tumor cells, and a secondary colonization process $(1,2)$. The former process is well known while the latter requires further study to elucidate multiple issues, including how altered proteins and intracellular signaling molecules induce epithelial mesenchymal transition (EMT).

Multiple novel drugs have been identified, including molecular targeted drugs, however the lung cancer mortality rate remains high $(3,4)$. The current clinical drugs for lung cancer are primarily epidermal growth factor receptor (EGFR)-tyrosine kinase inhibitors. However, multiple EGFR mutations during lung cancer cause drug resistance. Following screening of gene expression in lung cancer tumor tissue, basic fibroblast growth factor (bFGF), fibroblast growth factor receptor (FGFR)1 and FGFR 2 have been demonstrated to exhibit high expression levels, and be associated with drug resistance in lung cancer (5-7). There are fewer FGFR mutations in lung cancer, thus bFGF-FGFR is a reliable potential target.

Previous studies have suggested that FGFRs, in particular FGFR1, demonstrate high expression levels in lung cancer $(8,9)$. This effect is achieved by enhancing the affinity of FGFR to its ligand through increasing the number of gene copies and gene mutations. Furthermore, bFGF collaborates with other factors to strengthen the involvement of the bFGF-FGFR signaling pathway (10-13). For example, during the EMT process, transforming growth factor- $\beta$ induced isoform switching of FGFRs, causing the cells to become sensitive to bFGF (14). Similarly, the FGF-phosphoinositide 3-kinase-protein kinase B (AKT)-glycogen synthase kinase $3 \beta$ (GSK3 $\beta$ ) signaling pathway regulates EMT and increases the invasiveness of tumor cells (2).

In the initial stages of tumorigenesis, there are junctions between tumor cells and normal epithelial tissues, including tight junctions, adhesion junctions, gap junctions and desmosomes. These junctions limit the movement of tumor cells to form a complete tissue. With the development of cancer and deterioration, certain surface adhesion molecules of tumor cells are altered and the normal junctions between cells are lost. E-cadherin is involved in this process (15). The adherent junctions mediated by E-cadherin are not a static structure, however are a dynamic one. It has previously been suggested 
that FGF signaling promotes EMT through downregulating the expression of E-cadherin (16).

In the present study, a mouse monoclonal antibody against human bFGF was produced, targeting the binding site of bFGF with FGFR1. The monoclonal antibody (mAb) E12 inhibited Lewis lung carcinoma (LLC) metastasis through increasing the expression of E-cadherin via the AKT-GSK3- $\beta$-snail family transcriptional repressor 1 (Snail) pathway, suggesting that $\mathrm{mAbE} 12$ may be a promising anticancer antibody.

\section{Materials and methods}

Mouse Lewis lung carcinoma cells (LLC) and mouse myeloma cells (SP2/0) were maintained in the Guangdong Province Key Laboratory of Molecular Immunology and Antibody Engineering (Guangzhou, China). Dulbecco's modified Eagle's medium (DMEM) and fetal bovine serum (FBS) were purchased from Gibco; Thermo Fisher Scientific, Inc. (Waltham, MA, USA). TRIzol reagent, and the M-MLV First-Strand cDNA Synthesis kit were purchased from Thermo Fisher Scientific, Inc. Blend Taq-Plus and Cell Counting Kit-8 (CCK-8) were purchased from Toyobo Co., Ltd. (Osaka, Japan). AKT rabbit mAb (catalog no. 4685S), phosphorylated (p) -AKT rabbit mAb (\# 13038S), GSK3- $\beta$ rabbit mAb (catalog no. 5676S), p-GSK3- $\beta$ rabbit mAb (catalog no. 9322S), Snail mAb (catalog no. 3879S), E-cadherin mAb (catalog no. 3195S) and goat anti-rabbit immunoglobulin $\mathrm{G}(\mathrm{IgG})$ conjugated with horseradish peroxidase (HRP) antibodies (catalog no. 7074S) were purchased from Cell Signaling Technology, Inc. (Danvers, MA, USA). Balb/c mice and C57BL/6 mice were purchased from the Southern Medical University Animal Centre (Guangzhou, China). Male Balb/c mice and C57BL/6 mice (2-month old, 18-25 g, n=5) were housed in a $12 \mathrm{~h}$ dark and light cycle with free access to water and food, at a temperature of $26^{\circ} \mathrm{C}$ and humidity of $40-60 \%$. All efforts were made to minimize suffering. The pMD18-T plasmid vector was purchased from Takara Bio, Inc. (Otsu, Japan).

Animal immunization and cell fusion. A total of 5 Balb/c mice were immunized with recombinant human $\mathrm{bFGF}$, and then the mice were sacrificed after anesthesia (2\% pelltobarbitalum natricum, $50 \mathrm{mg} / \mathrm{kg}$, intraperitoneal injection) and B cells were harvested from the spleen of mice and fused with SP2/0 mouse myeloma cells. Hybridoma cell lines secreting $\mathrm{mAb}$ against the binding site of bFGF with FGFR1III ${ }_{C}$ were screened out by indirect and competitive enzyme linked immunosorbent assay (provided in house by the Antibody Engineering laboratory (Guangzhou, China). The present study was approved by the Laboratory Animal Ethics Committee of Jinan University (Guangzhou, China) and animal experiments were performed in compliance with the guidelines for the Welfare of Experimental Animals in Jinan University.

Indirect ELISA. Recombinant human bFGF (50 ng/well; Department of Anesthesia and Perioperative Care, University of California, USA) was used to coat microtiter ELISA wells. The ELISA wells were blocked with $5 \%$ non-fat dry milk in PBS buffer containing 0.5\% Tween-20 for $1 \mathrm{~h}$ at $37^{\circ} \mathrm{C}$, bFGF incubated with purified antibody (purified with Protein G Sepharose (GE Healthcare, Chicago, IL, USA; catalog no. $17-0405-03,1: 400,000)$ at $37^{\circ} \mathrm{C}$ for $1 \mathrm{~h}$, then HRP-conjugated goat anti-mouse antibody $(1: 8,000)$ at $37^{\circ} \mathrm{C}$ for $40 \mathrm{~min}$. The absorbance values were measured at $450 \mu \mathrm{m}$ on an automatic plate reader.

Competitive ELISA. The conditions used for competitive ELISA were maintained according to the method of the Indirect ELISA. ELISA wells containing bFGF were incubated with purified bFGF antibody $(1,400,000)$ and biotin-FGFR1III ${ }_{C}$ (1 $\mu \mathrm{g} / \mathrm{ml}$, Department of Anesthesia and Perioperative Care, University of California) at $37^{\circ} \mathrm{C}$ for $1 \mathrm{~h}$. HRP-conjugated streptavidin (catalog no. N100; 1:1,000; Thermo Fisher Scientific, Inc.) was incubated at $37^{\circ} \mathrm{C}$ for $40 \mathrm{~min}$. The absorbance values were measured at $450 \mu \mathrm{m}$ on an automatic plate reader.

bFGF mAb production and identification. The hybridoma cell lines secreting $\mathrm{mAb}$ against $\mathrm{bFGF}$ were cloned, and ascites were produced by injecting $1 \times 10^{5}$ hybridoma cells into 5 $\mathrm{Balb} / \mathrm{c}$ mice respectively. The $\mathrm{mAb}$ in the ascites was purified using affinity chromatography with Protein G Sepharose (GE Healthcare), and the elution buffer $(\mathrm{pH}=2.5)$ contained $150 \mathrm{mM}$ glycine-PBS buffer. And then identified by $12 \%$ SDS-PAGE.

Total RNA of the hybridoma cells secreting mAb against bFGF was extracted using TRIzol reagent, according to the manufacturer's protocol. The concentration of the extracted RNA was detected using a Nanodrop 2000 (Thermo Fisher Scientific, Inc.) at an absorbance of $260 \mathrm{~nm}$ (A260), the quality was detected by a ratio of A260/A280 and agarose gel electrophoresis ( $1 \mu \mathrm{g}$ per lane). cDNA was synthesized using the M-MLV First-Strand cDNA Synthesis kit (Thermo Fisher Scientific, Inc., catalog no. 28025013), according to the manufacturer's protocol. The genes of the mAb heavy chain and light chain were amplified by Blend Taq-Plus (Toyobo Co., Ltd., Osaka, Japan; catalog no. BTQ-201), according to the manufacturer's protocol. The primers of the DNA sequences were as follows: Heavy chain forward, 5'-TGAGGAGACGGTGACCGTGGTCCC-3' and reverse, 5'-GAGGTGCAGCTTCAGGAGTCAGG-3'; light chain forward, 5'-TTTGATTTCCAGCTTGGTGCCTCC-3' and reverse, 5'-GACATTGTGATGWCACAGTCTCC-3'. The reagents in the reaction were as follows: 10X buffer $(5 \mu \mathrm{l})$, $2 \mathrm{mM}$ dNTP $(5 \mu \mathrm{l})$, forward primer $(10 \mathrm{pmol} / \mu \mathrm{l} ; 1 \mu \mathrm{l})$, reverse primer $(10 \mathrm{pmol} / \mu \mathrm{l} ; 1 \mu \mathrm{l})$, cDNA $(1 \mu \mathrm{l})$, Blend Taq-Plus (2.5 U/ $\mu \mathrm{l} ; 0.5 \mu \mathrm{l}) \mathrm{ddH}_{2} \mathrm{O}(36.5 \mu \mathrm{l})$. The cycling conditions were as follows: Denaturation at $94^{\circ} \mathrm{C}$ for $5 \mathrm{mins}$ on the initial cycle and for $30 \mathrm{sec}$ for the rest, annealing at $56^{\circ} \mathrm{C}$ for $30 \mathrm{sec}$ and extension at $72^{\circ} \mathrm{C}$ for $40 \mathrm{sec}$; with an additional $10 \mathrm{~min}$ extension on the last cycle. The number of cycles was 35 . The genes of the mAb heavy and light chains were inserted and ligated into the pMD18-T vector (Takara Bio, Inc., catalog no. 6011). The $\mathrm{mAb}$ variable region sequence was analyzed by the Beijing Genomics Institute (Beijing, China).

Analysis of the binding sites of antibody fragment of variable region $(F v), F G F R 1$ and $b F G F$. Discovery Studio 4.0 software (Accelrys Ltd., Cambridge, UK) was used in homology modeling, molecular docking and three-dimensional structure building of the antibody Fv. This three-dimensional structure 
Table I. Hybridoma screening by ELISA.

\begin{tabular}{lcccc}
\hline Name & Cell supernatant dilution ratio & Ascite dilution ratio & Competitive rate (\%) & Antibody isotype \\
\hline 1A6 (mAbA6) & $1: 600$ & $1: 700,000$ & $22.77 \pm 1.8$ & IgG1 \\
2D9 (mAbD9) & $1: 1,000$ & $1: 800,000$ & $31.56 \pm 0.7$ & IgG1 \\
5F10 (mAbF10) & $1: 400$ & $1: 500,000$ & $23.77 \pm 0.7$ & IgG1 \\
2E12 (mAbE12) & $1: 800$ & $1: 400,000$ & $34.51 \pm 0.6$ & IgG1
\end{tabular}

mAb, monoclonal antibody; IgG, immunoglobulin G.

A

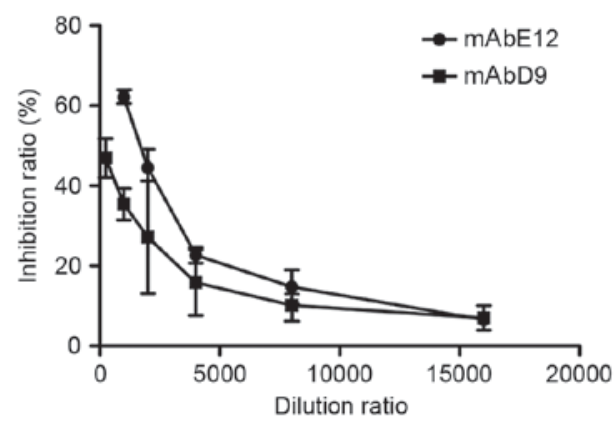

B

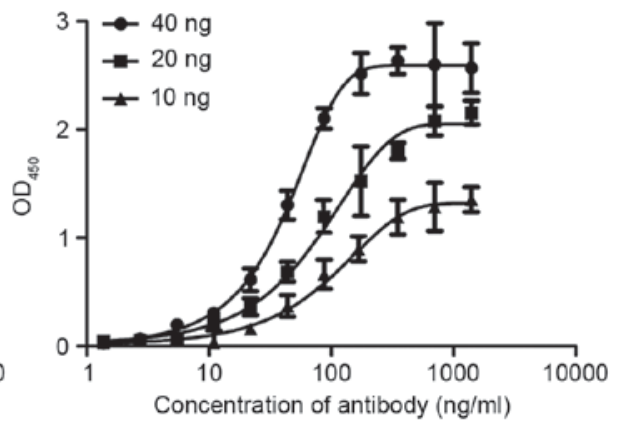

Figure 1. Identification of purified antibody. (A) Inhibition ratio of bFGF binding activity between bFGF antibody and FGF receptor $1 \beta \mathrm{FII}_{\mathrm{C}}$. (B) Measurement of relative affinity constant of mAbE12 antibody. Results are presented as the mean \pm standard deviation. bFGF, basic fibroblast growth factor; mAb, monoclonal antibody.

was used to analyze the binding site with bFGF. The binding sites of FGFR1 (ID: 4ZSA) and bFGF (ID: 4OEG) were then downloaded from the Protein Data Bank database to compare with this result.

Effect of $m A b$ on proliferation and migration of LLC cells. Cell suspension $(100 \mu \mathrm{l} ; 2,000$ cells/well) was dispensed in a 96-well plate and pre-incubated overnight in a $\mathrm{CO}_{2}$ incubator at $37^{\circ} \mathrm{C}$. Following this, the suspension was decanted into DMEM complete medium and 1, 10, 50, 200 and $300 \mu \mathrm{g} / \mathrm{ml}$ $\mathrm{mAb}$ was added into the low serum DMEM medium $(0.5 \%$ FBS) in the plate. The plate was incubated at $37^{\circ} \mathrm{C}$ and $5 \%$ $\mathrm{CO}_{2}$. CCK-8 solution $(10 \mu \mathrm{l})$ was added to each well following $72 \mathrm{~h}$ incubation. The plate was incubated for a further $2 \mathrm{~h}$ and the absorbance was measured at $450 \mathrm{~nm}$.

LLC cells $\left(100 \mu \mathrm{l} ; 5 \times 10^{5}\right.$ cells $/ \mathrm{ml}$ with $200 \mu \mathrm{g} / \mathrm{ml} \mathrm{bFGF}$ $\mathrm{mAb})$ and $600 \mu \mathrm{l}$ DMEM complete medium (10\% FBS, $20 \mathrm{ng} / \mathrm{ml} \mathrm{bFGF}$ and $200 \mu \mathrm{g} / \mathrm{ml} \mathrm{bFGF} \mathrm{mAb})$ were placed in the upper and lower chamber of Transwell plates, respectively, as the experimental group. LLC cells $\left(100 \mu \mathrm{l} ; 5 \times 10^{5}\right.$ cells $\left./ \mathrm{ml}\right)$ LLC cells and $600 \mu \mathrm{l}$ DMEM complete medium (10\% FBS, $20 \mathrm{ng} / \mathrm{ml} \mathrm{bFGF}$ ) were placed in the upper and lower chamber, respectively, as the medium group. LLC cells $\left(100 \mu 1 ; 5 \times 10^{5}\right.$ cells $/ \mathrm{ml}$ ) and $600 \mu \mathrm{l}$ DMEM complete medium (10\% FBS, $20 \mathrm{ng} / \mathrm{ml} \mathrm{bFGF}$ and $200 \mu \mathrm{g} / \mathrm{ml}$ control $\mathrm{IgG}$ ) were placed in the upper and lower chamber, respectively, as the control group. The chamber was incubated for $24 \mathrm{~h}$, following which the cells were washed twice with PBS to remove unattached cells. The remaining cells were fixed with $10 \%$ formaldehyde for $30 \mathrm{~min}$. Following this, the cells were stained with crystal violet for $20 \mathrm{~min}$ and the migrating cells were counted using a light microscope manually by 4 researchers in 5 fields of view in each chamber.

Western blot analysis of signaling pathway. LLC cells were seeded in 6-well plates containing $0.5 \%$ FBS in DMEM medium $\left(3 \times 10^{5}\right.$ cells/well). Following being starved and treated with $1,10,50$ or $200 \mu \mathrm{g} / \mathrm{ml}$ bFGF mAb or $1,10,50$ or $200 \mu \mathrm{g} / \mathrm{ml}$ control $\mathrm{IgG}$ for $24 \mathrm{~h}$, protein was harvested from $3 \times 10^{5}$ LLC cells using RIPA lysis buffer (Beyotime Institute of Biotechnology, Haimen, China; catalog no. P0013C). The concentration of the protein was measured with the BCA protein assay kit (Thermo Fisher Scientific, Inc., catalog no. 23225$)$. Protein $(30 \mu \mathrm{g})$ was separated by $10 \%$ SDS-PAGE $(100 \mathrm{~V} ; 70 \mathrm{~min})$ and transferred to a polyvinyldene fluoride membrane. The membrane was blocked with $5 \%$ non-fat dry milk in PBS buffer containing $0.5 \%$ Tween-20 for $1 \mathrm{~h}$ at $37^{\circ} \mathrm{C}$, and incubated with primary antibody (E-cadherin rabbit $\mathrm{mAb}$, p-Akt, AKT rabbit mAb, p-GSK3- $\beta$, GSK-3 $\beta$ rabbit mAb, Snail rabbit $\mathrm{mAb} ; 1: 1,000)$ at $37^{\circ} \mathrm{C}$ for $2 \mathrm{~h}$, and $\mathrm{HRP}$-conjugated secondary antibody $(1: 8,000)$ at $37^{\circ} \mathrm{C}$ for $1 \mathrm{~h}$. The blots were also probed with $\beta$-actin $(1: 1,000$; catalog no. 4970$)$ at $37^{\circ} \mathrm{C}$ for $2 \mathrm{~h}$ as a control.

Xenograft studies of LLC cells. A single-cell suspension $\left(1 \times 10^{6}\right.$ cells $\left./ \mathrm{ml}\right)$ of LLC cells was prepared and $50 \mu \mathrm{l}$ subcutaneously injected into the back of the C57BL/6 mice. Once the tumors reached $\sim 3 \mathrm{~mm}^{3}$ volume, mice were distributed randomly into two groups $(n=5)$. The experimental group was injected with $1 \mathrm{mg}$ bFGF $\mathrm{mAb}$ and the control group was injected with $1 \mathrm{mg}$ control $\mathrm{IgG}$ every 3 days, around the tumor. All mice were anesthetized ( $2 \%$ pelltobarbitalum natricum; 
A

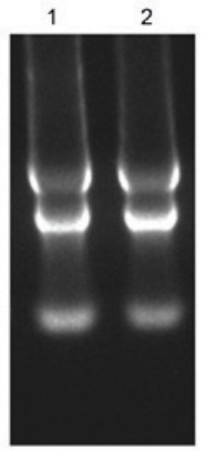

B

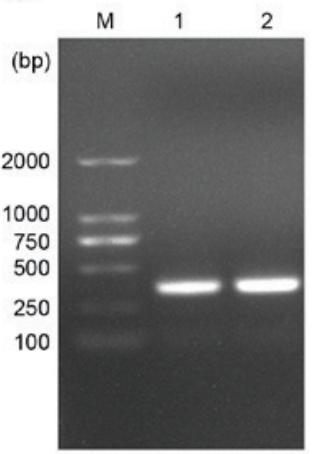

C

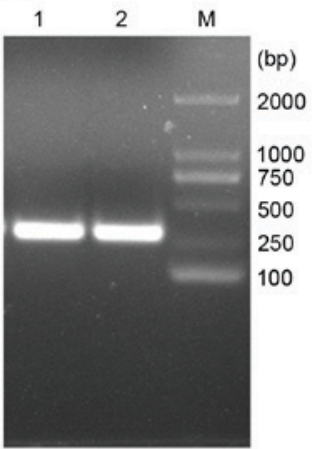

D
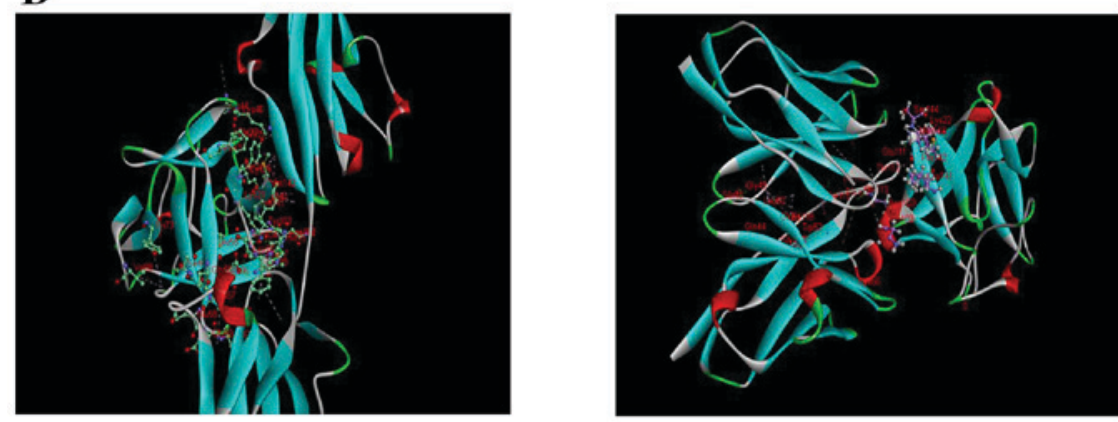

$\mathbf{E}$

FGFR1-bFGF: 2-Lys, 5-Tyr, 7-Lys, 9, 10-Gly, 37-43 (LQAEERG), 82-85 (NNYN), 120-122 (LPM)

Fv-bFGF: 2-Lys, 82-85 (NNYN),120-122 (LPMS)

Figure 2. Fv of mAbE12 antibody (A) Identification of isolated RNA. Reverse transcription polymerase chain reaction amplification of mAbE12 (B) heavy chain and (C) light chain Fv. (D) Three dimensional images of Fv fragment of mAbE12-bFGF and FGFR1-bFGF. The red part of the three-dimensional structures was the common binding site. (E) Comparison of binding sites between Fv-bFGF and FGFR1-bFGF. Fv, fragment of variable region; mAb, monoclonal antibody; bFGF, basic fibroblast growth factor; FGFR1, fibroblast growth factor receptor 1.

A

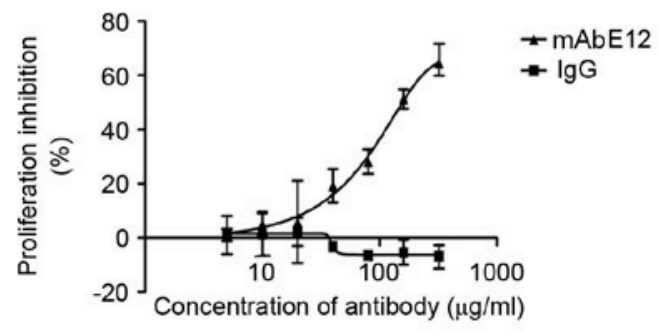

B

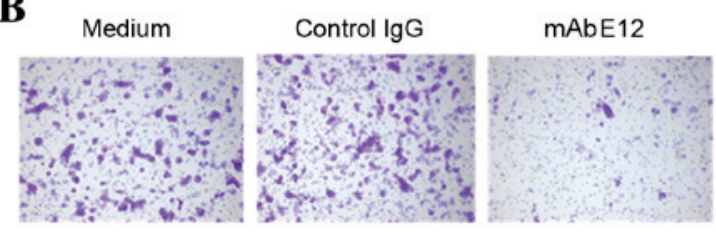

Figure 3. Effect of mAbE12 on (A) Lewis lung carcinoma cell proliferation and (B) migration. Results are presented as the mean \pm standard deviation. $\mathrm{mAb}$, monoclonal antibody; IgG, immunoglobulin $\mathrm{G}$.

Sigma-Aldrich, Merck KGaA, Darmstadt, Germany; catatlog no. P3761; $50 \mathrm{mg} / \mathrm{kg}$; intraperitoneal injection) and sacrificed following 6 injections. The lungs were removed and fixed with Bouin solution (Huayueyang Biotechnology Co., Ltd., Beijing,

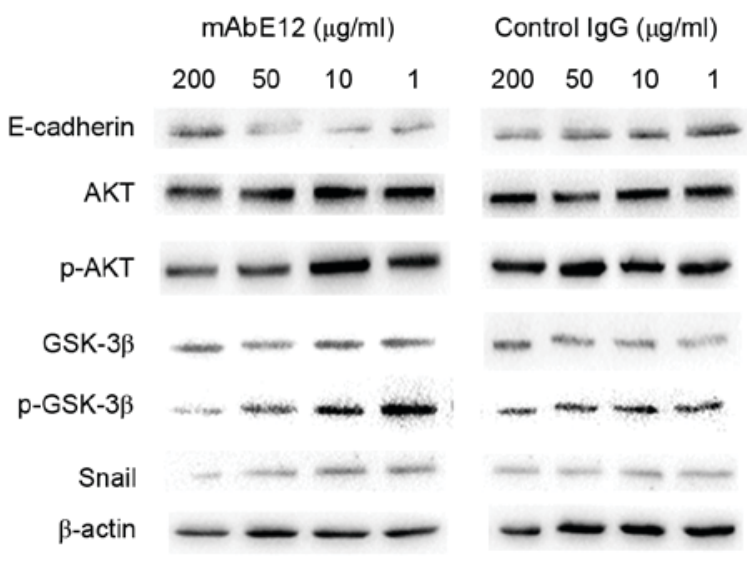

Figure 4 . The AKT/GSK3- $\beta /$ Snail pathway was suppressed by mAbE12. A dose-dependent decrease of $\mathrm{p}$-AKT was observed in the $\mathrm{mAbE} 12$ group. The expression of Snail was downregulated and the expression of E-cadherin was upregulated in the mAbE12 group. $\beta$-actin served as a control. AKT, protein kinase B; p-, phosphorylated; Snail, snail family transcriptional repressor 1; GSK3- $\beta$, glycogen synthase kinase $3 \beta$; mAb, monoclonal antibody.

China; catalog no. WX0180) at $4^{\circ} \mathrm{C}$ for $24 \mathrm{~h}$, then metastatic nodules were identified. The tumors from the $\mathrm{mAbE} 12$-treated and control groups were harvested and the volume and weight of the tumors was measured. 
A

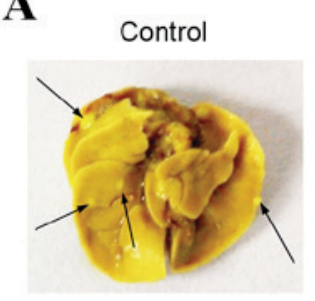

mAbE12

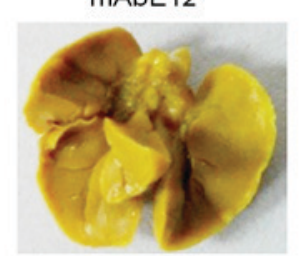

B

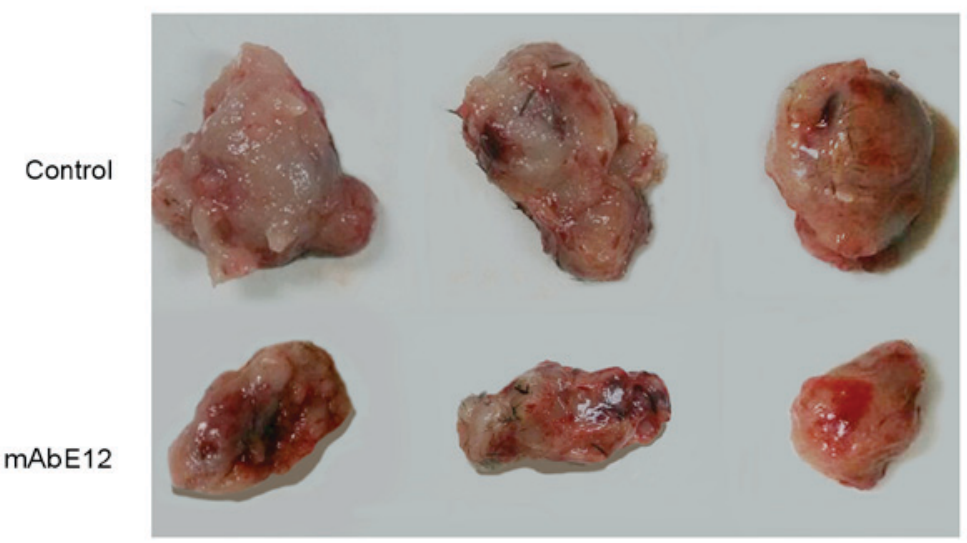

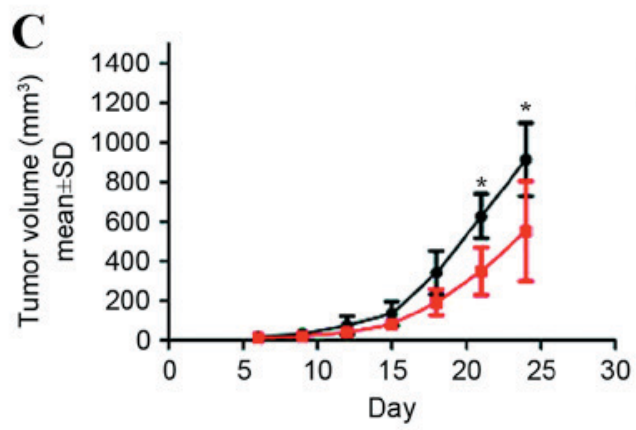

Figure 5. Effect of mAb on LLC metastasis and growth in vivo. (A) Lung metastatic colonies of LLC cells with different treatments. Arrows indicate the metastatic foci in the lungs. (B) Inhibition of LLC tumor growth induced by mAbE12. (C) Tumor growth curve of mAbE12 and PBS control group. Data are presented as the mean \pm SD. * $\mathrm{P}<0.05$ vs. PBS control. mAb, monoclonal antibody; LLC, Lewis lung carcinoma; SD, standard deviation; PBS, phosphate-buffered saline.

Statistical analysis. All numerical data are presented as the mean \pm standard deviation. Statistical differences were evaluated with the Mann-Whitney U test for comparison between the groups. Analysis was conducted using SPSS software, version 20.0 (IBM Corp., Armonk, NY, USA). GraphPad Prism version 6 software (GraphPad Software, Inc, La Jolla, CA, USA) was used to create the graphs from the statistical analysis. $\mathrm{P}<0.05$ was considered to indicate a statistically significant difference.

\section{Results}

Hybridoma cell screening and identification of purified antibodies. 4 hybridoma cells were screened out by indirect and competitive ELISA. The competitive ELISA used cell supernatants, containing bFGF antibody, to compete with FGFR1. Of the antibodies, mAbD9 and mAbE12 demonstrated increased competitive ability compared with mAbA6 and mAbE10. The titer and the isotype of the antibodies are summarized in Table I. In order to determine the most competitive antibody, mAbD9 and mAbE12, purified mAbD9 and mAbE12 were used to compete with FGFR1. The IC50 of mAbE12 and mAbD9 were 1.96 and $1.564 \mu \mathrm{g} / \mathrm{ml}$, respectively (Fig. 1A). mAbE12 was therefore more competitive than mAbD9, and mAbE12 was selected as the experimental antibody. The relative affinity of the $\mathrm{mAbE} 12$ antibody was measured using indirect ELISA. The relative affinity of mAbE12 antibody was $\mathrm{K}_{\mathrm{aff}}=5.66 \times 10^{8} \mathrm{l} / \mathrm{mol}$ (Fig. 1B).
Fv of mAbE12 antibody. The total RNA of mAbE12 hybridoma cells was extracted (Fig. 2A) and reverse transcribed into cDNA. The heavy chain variable region and light chain variable region were $\sim 300$ bp long (Fig. 2B and $\mathrm{C}$, respectively). In order to study the structure of $\mathrm{mAbE} 12$, Discovery Studio 4.0 software was used to model the homology, molecular docking and build three-dimensional structures of the Fv region. The binding sites of the Fv fragment of mAbE12-bFGF and bFGF-FGFR1 were also analyzed by Discovery Studio 4.0 software (Fig. 2D). The red part of the three-dimensional structures was the common binding site of Fv-bFGF and FGFR1-bFGF. Therefore, it was concluded Fv-bFGF had the same binding site as FGFR1-bFGF (Fig. 2E).

Effect of $m A b$ on LLC cell proliferation and migration. The results of the CCK- 8 assay indicated that LLC cell proliferation is inhibited by $\mathrm{mAbE} 12$, and the most efficient $\mathrm{mAb}$ concentration was $300 \mu \mathrm{g} / \mathrm{ml}$ (Fig. 3A) The IC50 of proliferation inhibition was $119.97 \pm 40.96 \mu \mathrm{g} / \mathrm{ml}$ (Fig. 3A). A stronger reduction of migrating cells was observed in the $\mathrm{mAbE12}$ group compared with the IgG control group and the medium group. The migration rates were $45.73 \pm 7.98,121.67 \pm 24.52$ and $100 \%$ for the $\mathrm{mAbE} 12, \mathrm{IgG}$ control and medium groups, respectively (Fig. 3B).

Effect of $m A b$ on the LLC cell signaling pathway. Snail expression and phosphorylation of AKT(T-308) and GSK3- $\beta$ 
(Ser-9) were visibly suppressed by treatment with 50 or $200 \mu \mathrm{g} / \mathrm{ml} \mathrm{mAbE12}$. No visible difference was observed in the IgG control group. E-cadherin expression was upregulated in the 50 and $200 \mu \mathrm{g} / \mathrm{ml} \mathrm{mAbE12} \mathrm{experimental} \mathrm{group} \mathrm{but}$ remained unchanged in the $\mathrm{IgG}$ control group. This suggested that mAbE12 downregulated the phosphorylation of AKT and GSK3- $\beta$, downregulated Snail and upregulated E-cadherin protein levels. The suppression of the AKT/GSK3- $\beta /$ Snail pathway signaling and the reduction in the number of migrating cells indicated that $\mathrm{mAbE} 12$ inhibited tumor metastasis through suppressing the AKT/GSK3- $\beta /$ Snail pathway and upregulating the expression of E-cadherin, enhancing cell-cell junctions.

Effect of $m A b$ on LLC cell metastasis and growth in vivo. The lung colonization assay and xenograft tumor formation assay indicated that treatment of mice with mAbE12 led to a decrease in lung metastasis (Fig. 5A) and a reduction of tumor growth (Fig. 5B and C). These results demonstrated that mAbE12 inhibited the metastasis of LLC cells and tumor growth in vivo.

\section{Discussion}

At present, small molecular compounds are used during drug treatment for patients with cancer. These have demonstrated efficacy, however also present with serious side effects. Targeted therapy, in particular antibody therapy, has provided a novel method to address this issue. Hybridoma and phage display technology are the main methods for preparing monoclonal antibodies at present (17). The present study adopted classical hybridoma technology and competitive ELISA with an avidin-biotin amplification system to screen antibodies. mAbE12, mAbD9, mAbA6 and mAbF10 cells, which are capable of secreting bFGF monoclonal antibodies, were screened. The results of the competitive ELISA demonstrated that the competitive abilities of these antibodies were different, potentially due to differences in affinity or epitope of these antibodies. mAbE12 was selected as the most competitive antibody. Initially, the reverse transcription polymerase chain reaction was used to amplify the Fv region gene. Subsequently, Discovery Studio 4.0 software was used for homology modeling, molecular docking and three-dimensional structure building. Following this, the binding site with $\mathrm{bFgF}$ was analyzed. The results indicated that the binding site of Fv-bFGF was similar to the binding site of FGFR1-bFGF. This further confirmed that mAbE12 screened in the present study is the target antibody for the binding site of FGFR1-bFGF, and its weak competitive ability is potentially due to its weak affinity. It also suggested that the competitive ELISA screening method established in the present study was accurate. Discovery Studio software also predicts the amino acid mutation site of the antibody, which makes it possible to then improve the affinity by site-directed mutagenesis. In future studies, Discovery Studio software should be used to predict the amino acid mutation sites and improve the affinity of the antibody.

Changes to tumor cell morphology and a variety of surface molecules is the basis of tumor metastasis. bFGF promotes the process of tumor metastasis (18). Therefore, the inhibition of the biological functions of bFGF should have an inhibitory effect on tumor metastasis. LLCs with high expression levels of bFGF and FGFR1 were selected as the object of the present study. Furthermore, LLC cell migration was decreased following treatment with mAbE12 compared with the IgG control group, which may be due to the upregulation of E-cadherin expression. E-cadherin is involved in cell interaction and signal transduction. Tumor development and progression are associated with loss or downregulation of E-cadherin. This phenomenon is often associated with changes of tumor cell morphology, metastasis and invasion $(19,20)$. The results of in vivo and in vitro experiments demonstrated that bFGF antibody upregulates the expression level of E-cadherin, which may be one mechanism underlying the inhibition of tumor metastasis by bFGF mAb.

E-cadherin-mediated cell adhesion is associated with epithelial morphology. The loss of E-cadherin results in the acquisition of metastatic potential in tumor cells. The loss or downregulation of E-cadherin has been observed in variety of malignancies (21). In the present study, the phosphorylation level of AKT and GSK3- $\beta$ were decreased when the antibody concentration was increased. The nuclear transcription factor Snail was also downregulated when treated with mAbE12 antibody. Therefore, it is possible to hypothesize that bFGF antibody upregulates E-cadherin expression in LLC, primarily by inactivating AKT, resulting in GSK3- $\beta$ activation and degradation of Snail. When the nuclear transcription factor Snail is degraded by activated GSK3- $\beta$, the expression of E-cadherin will increase.

In the present study, mAbE12 antibodies were demonstrated to bind naturally expressed bFGF in LLC cells, specifically, and to inhibit the growth of LLC cells. Furthermore, mAbE12 blocked signaling pathways activated by bFGF, inhibited proliferation, and resulted in a reduction in tumor growth and lung metastasis. The primary mechanism by which this occurred was the upregulation of E-cadherin expression through regulation of the AKT-GSK3- $\beta$-Snail pathway. Understanding the mechanism of E12 may aid the identification of novel therapies for cancer.

\section{Acknowledgements}

The authors would like to thank Professor James D Marks (University of California, San Francisco, CA, USA) for providing the empirical method used to clone the bFGF $\mathrm{mAb} F v$ fragment and the humanized bFGF mAb genes. The present study was supported by the State Natural Science Foundation Youth Science Foundation of China (grant no. 81202449).

\section{References}

1. Schiller JH, Harrington D, Belani CP, Langer C, Sandler A, Krook J, Zhu J and Johnson DH; Eastern Cooperative Oncology Group: Comparison of four chemotherapy regimens for advanced non-small-cell lung cancer. N Engl J Med 346: 92-98, 2002.

2. Chaffer CL and Weinberg RA: A perspective on cancer cell metastasis. Science 331: 1559-1564, 2011.

3. Rades D, Setter C, Dahl O, Schild SE and Noack F: Fibroblast growth factor 2-a predictor of outcome for patients irradiated for stage II-III non-small-cell lung cancer. Int J Radiat Oncol Biol Phys 82: 442-447, 2012.

4. Sandler A, Gray R, Perry MC, Brahmer J, Schiller JH, Dowlati A, Lilenbaum R and Johnson DH: Paclitaxel-carboplatin alone or with bevacizumab for non-small-cell lung cancer. N Engl J Med 355: 2542-2550, 2006. 
5. Azuma K, Kawahara A, Sonoda K, Nakashima K, Tashiro K, Watari K, Izumi H, Kage M, Kuwano M, Ono M and Hoshino T: FGFR1 activation is an escape mechanism in human lung cancer cells resistant to afatinib, a pan-EGFR family kinase inhibitor. Oncotarget 5: 5908-5919, 2014.

6. Strutz F, Zeisberg M, Ziyadeh FN, Yang CQ, Kalluri R, Müller GA and Neilson EG: Role of basic fibroblast growth factor-2 in epithelial-mesenchymal transformation. Kidney Int 61: 1714-1728, 2002.

7. Ribatti D, Vacca A, Rusnati M and Presta M: The discovery of basic fibroblast growth factor/fibroblast growth factor-2 and its role in haematological malignancies. Cytokine Growth Factor Rev 18: 327-334, 2007.

8. Tiong KH, Mah LY and Leong CO: Functional roles of fibroblast growth factor receptors (FGFRs) signaling in human cancers. Apoptosis 18: 1447-1468, 2013.

9. Tomlinson DC and Knowles MA: Altered splicing of FGFR1 Is associated with high tumor grade and stage and leads to increased sensitivity to FGF1 in bladder cancer. Am J Pathol 177: 2379-2386, 2010

10. Katoh M: Cancer genomics and genetics of FGFR2 (Review). Int J Oncol 33: 233-237, 2008.

11. Preusser M, Berghoff AS, Berger W, Ilhan-Mutlu A, Dinhof C, Widhalm G, Dieckmann K, Wöhrer A, Hackl M, von Deimling A, et al: High rate of FGFR1 amplifications in brain metastases of squamous and non-squamous lung cancer. Lung Cancer 83: 83-89, 2014.

12. Billottet C, Elkhatib N, Thiery JP and Jouanneau J: Targets of fibroblast growth factor 1 (FGF-1) and FGF-2 signaling involved in the invasive and tumorigenic behavior of carcinoma cells. Mol Biol Cell 15: 4725-4734, 2004
13. Dey JH, Bianchi F, Voshol J, Bonenfant D, Oakeley EJ and Hynes NE: Targeting fibroblast growth factor receptors blocks PI3K/AKT signaling, induces apoptosis, and impairs mammary tumor outgrowth and metastasis. Cancer Res 70: 4151-4162, 2010.

14. Shirakihara T, Horiguchi K, Miyazawa K, Ehata S, Shibata T, Morita I, Miyazono K and Saitoh M: TGF- $\beta$ regulates isoform switching of FGF receptors and epithelial-mesenchymal transition. Embo J 30: 783-795, 2011.

15. Kalluri R and Weinberg RA: The basics of epithelial-mesenchymal transition. J Clin Invest 119: 1420-1428, 2009

16. Ciruna B and Rossant J: FGF signaling regulates mesoderm cell fate specification and morphogenetic movement at the primitive streak. Dev Cell 1: 37-49, 2001

17. Weisser NE and Hall JC: Applicantions of single-chain variable fragment antibodies in therapeutics and diagnostis. Biotechnol Adv 27: 502-520, 2009.

18. Zohn IE,Li YQ, SkolnikEY, Anderson KV, Han J and Niswander L: p38 and a p38-interacting protein are critical for downregulation of E-cadherin during mouse gastrulation. Cell 125: 957-969, 2006.

19. Parsons JT, Horwitz AR and Schwartz MA: Cell adhesion: Integrating cytoskeletal dynamics and cellular tension. Nat Rev Mol Cell Bio 11: 633-643, 2010.

20. Shi YD, Felley-Bosco E, Marti TM, Orlowski K, Pruschy M and Stahel RA: Starvation-induced activation of ATM/Chk2/p53 signaling sensitizes cancer cells to cisplatin. BMC Cancer 12: $571,2012$.

21. Dong S, Khoo A, Wei J, Bowser RK, Weathington NM, Xiao S, Zhang L, Ma H, Zhao Y and Zhao J: Serum starvation regulates E-cadherin upregulation via activation of c-Src in non-small-cell lung cancer A549 cells. Am J Physiol Cell Physiol 307: C893-C899, 2014. 